\title{
Macrocytic anemia is associated with the severity of liver impairment in patients with hepatitis B virus-related decompensated cirrhosis: a retrospective cross-sectional study
}

\author{
Jian Yang ${ }^{1+}\left(\mathbb{D}\right.$, Bin Yan ${ }^{1+}$, Lihong Yang ${ }^{1}$, Huimin $\mathrm{Li}^{2}$, Yajuan Fan ${ }^{2}$, Feng $\mathrm{Zhu}^{3}$, Jie Zheng ${ }^{1}$ and Xiancang $\mathrm{Ma}^{2^{*}}$
}

\begin{abstract}
Background: Macrocytic anemia is common in liver disease. However, its role in hepatitis B virus (HBV)-related decompensated cirrhosis remains unknown. The aim of the present study was to determine the association between macrocytic anemia and the severity of liver impairment in patients with HBV-related decompensated cirrhosis according to the Model for End Stage Liver Disease (MELD) score.
\end{abstract}

Methods: A total of 463 participants who fulfilled our criteria were enrolled in this cross-sectional study. Patients were classified into three groups according to anemia types, diagnosed based on their mean corpuscular volume level. Multivariate linear regression analyses were used to determine the association between macrocytic anemia and the MELD score for patients with HBV-related decompensated cirrhosis.

Results: Patients with macrocytic anemia had evidently higher MELD scores (10.8 \pm 6.6$)$ than those with normocytic anemia $(8.0 \pm 5.5)$ or microcytic anemia $(6.3 \pm 5.1)$. The association remained robust after adjusting for age, gender, smoking, drinking, and total cholesterol $(\beta=1.94, \mathrm{Cl}: 0.81-3.07, P<0.001)$.

Conclusions: Macrocytic anemia was found to be associated with the severity of liver impairment and might be a predictor for short-term mortality in patients with HBV-related decompensated cirrhosis.

Keywords: Macrocytic anemia, HBV-related decompensated cirrhosis, MELD score, Severity of liver impairment

\section{Background}

Cirrhosis is an end-stage disease that invariably leads to death. It is the 14th most common cause of death in adults worldwide and results in 1.03 million deaths per year [1]. Chronic infection with hepatitis B virus (HBV) is one of the major causes of cirrhosis and 30\% of deaths are attributable to $\mathrm{HBV}[2,3]$. China is a highly endemic area of $\mathrm{HBV}$, where $78 \%$ of patients with cirrhosis are HBsAg positive [4]. In patients with cirrhosis, the 5-year probability of decompensation is $15-20 \%$, while the

\footnotetext{
* Correspondence: maxiancang@163.com

${ }^{\dagger}$ Jian Yang and Bin Yan contributed equally to this work.

${ }^{2}$ Department of Psychiatry, the First Affiliated Hospital, Xi'an Jiaotong

University, No.277 Yanta West Road, Yanta District, Xi'an 710061, People's

Republic of China

Full list of author information is available at the end of the article
}

5 -year survival rate decreases from 84 to $14-35 \%$ once clinical decompensating events occur [5-7].

Anemia is a common comorbidity in cirrhosis that is associated with poor prognosis [8]. Erythrocyte abnormalities were clinically important and frequent findings in patients with chronic disease. Mean corpuscular volume $(\mathrm{MCV})$, a measurement of the average volume of red blood cells (RBCs), has been documented to be associated with an increase in many clinical conditions [9-12]. Typically, anemia can be classified into macrocytic anemia (>100 fL), normocytic anemia (80-100 fL), and microcytic anemia $(<80 \mathrm{fL})$ based on the patient's MCV level. A recent study has reported that the elevated MCV level was associated with increased liver cancer mortality, especially in men who are hepatitis B surface antigen (HBsAg)

(c) The Author(s). 2018 Open Access This article is distributed under the terms of the Creative Commons Attribution 4.0 International License (http://creativecommons.org/licenses/by/4.0/), which permits unrestricted use, distribution, and reproduction in any medium, provided you give appropriate credit to the original author(s) and the source, provide a link to the Creative Commons license, and indicate if changes were made. The Creative Commons Public Domain Dedication waiver (http://creativecommons.org/publicdomain/zero/1.0/) applies to the data made available in this article, unless otherwise stated. 
positive [13]. Therefore, in this study, we hypothesized that a common association might exist between macrocytic anemia and the severity of liver impairment in patients with HBV-related decompensated cirrhosis.

We used the Model for End Stage Liver Disease (MELD) score for evaluating the severity of liver impairment of HBV-related decompensated cirrhosis. The MELD score was developed to predict the short-term mortality of end-stage liver disease because of the shortage of donated livers. It had been validated subsequently as an accurate predictor of survival among different populations of patients with advanced liver disease and was adopted for organ allocation for liver transplantation instead of the older Child-Pugh score in the USA since 2002 [14-16]. Liver transplantation is generally recommended for patients with MELD score of > 15, if possible [17].

The goal of the present study is to investigate whether the MELD score is higher in the macrocytic anemia group in patients with HBV-related decompensated cirrhosis.

\section{Methods}

\section{Study population}

From May 2013 to July 2016, data of 1445 patients diagnosed as having HBV-related decompensated cirrhosis were extracted from the HIS Database at the First Affiliated Hospital of Xi'an Jiaotong University. For patients to be diagnosed as having HBV-related decompensated cirrhosis, the following conditions must be present: HBsAg carrier for $\geq 6$ months; pathological or clinical evidence of cirrhosis; and occurrence of complications, such as ascites, upper gastrointestinal bleeding, spontaneous bacterial peritonitis, or hepatic encephalopathy $[6,18-20]$. Anemia was defined according to WHO's haemoglobin thresholds, which is haemoglobin level of $<130 \mathrm{~g} / \mathrm{L}$ in male and $<120 \mathrm{~g} / \mathrm{L}$ in female [8]. After strictly screening according to the inclusion criteria and exclusion criteria, 463 patients were enrolled in this hospital-based cross-sectional study (Fig. 1). The study was approved by the Ethics Committee of the First Affiliated Hospital, Xian Jiaotong University. Since this is a retrospective study, a written consent is waived by the Ethics Committee and is deemed unnecessary. All methods were carried out in accordance with appropriate clinical practice guidelines and national legal requirements.

\section{Data collection}

Demographic characteristics were obtained from an interview during the patients' admission to our hospital. Venous blood samples were collected from the participants after an overnight fasting for laboratory assessments. Smoking was defined as having $\geq 1$ cigarette per day and drinking was defined as alcohol intaking $>20 \mathrm{~g}$ per day for at least a year [21, 22]. Estimated glomerular filtration rate (eGFR) was calculated using a formula adapted from the Modification of Diet in Renal Disease (MDRD) equation [23, 24]. Unfortunately, body mass index (BMI) and HBV DNA data were not included in the analysis due to excessive missing values.

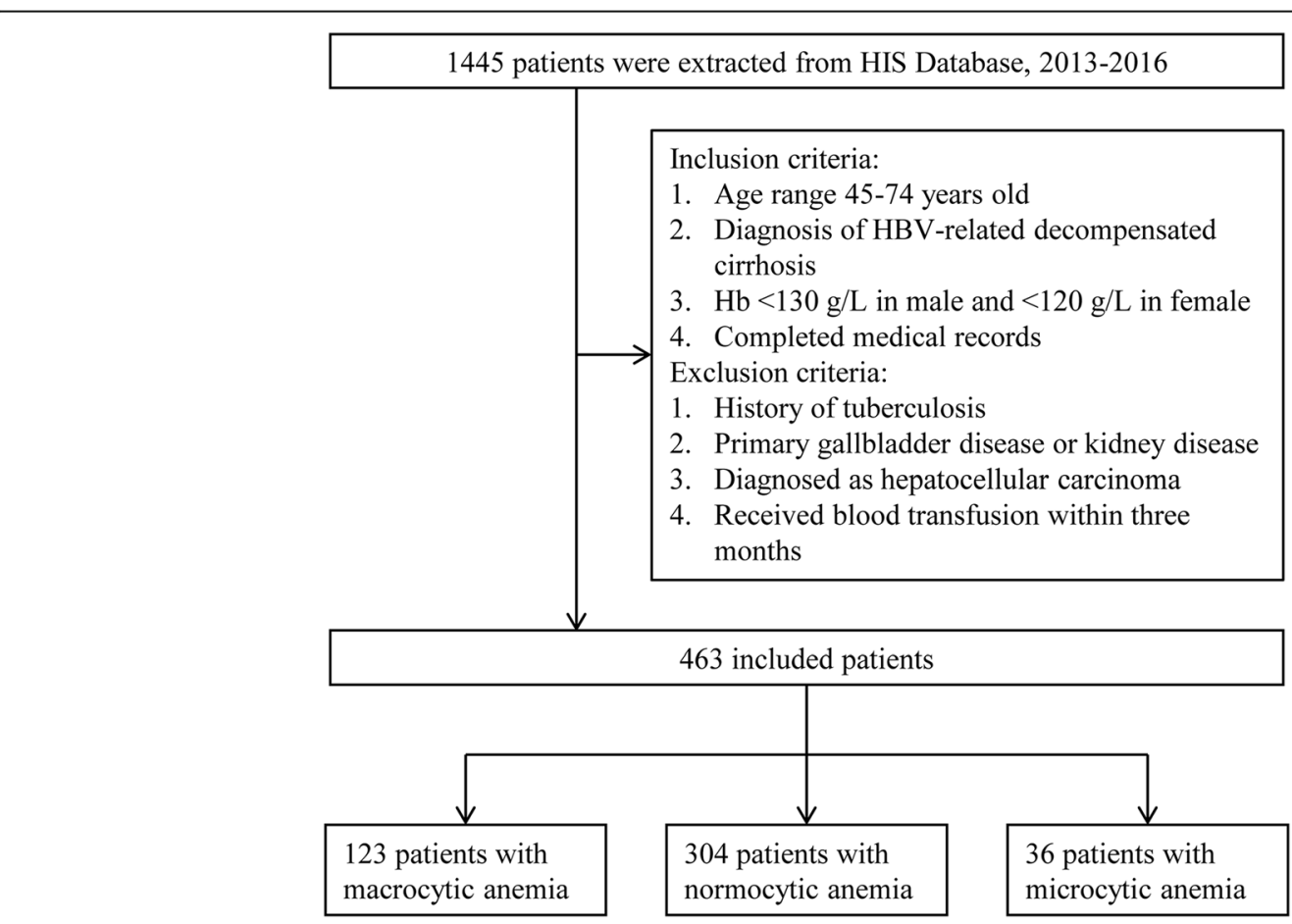

Fig. 1 Flow diagram for the selection of patients 


\section{MELD score}

The MELD score was calculated using the following formula: $9.57 \times \log _{\mathrm{e}}($ creatinine $\mathrm{mg} / \mathrm{dl})+3.78 \times \log _{\mathrm{e}}$ (bilirubin $\mathrm{mg} / \mathrm{dl})+11.2 \times \log _{\mathrm{e}}(\mathrm{INR})+6.43$, where INR is the international normalised ratio and 6.43 is the constant for liver disease aetiology [16].

\section{Statistical analysis}

Statistical analyses were conducted using $\mathrm{R}$ software (version 3.1.3). Continuous data were presented as mean $\pm \mathrm{SD}$, and categorical variables were presented as count and percentage. All participants were divided into three groups according to their anemia classification. We used one-way ANOVA to determine the differences among the three groups in terms of the continuous variables, because the variables were all normally distributed and homogeneous in variance. Simultaneously, the chi-square test was used for categorical variables. Univariate and multivariate linear regression analyses were used to examine the associations of the MELD score with macrocytic anemia. Variables with $P$ value $<0.05$ in univariate models were then included in the multivariate analyses. A two-tailed test was used to calculate the P value, and the results were considered statistically significant when the $P$ value $<0.05$.

\section{Results}

\section{Characteristics of participants}

Table 1 presents the baseline characteristics of the participants, which were divided into three groups according to anemia types. Among the 463 eligible participants, 304 had normocytic anemia, 123 had macrocytic anemia and 36 had microcytic anemia. The average age of participants was $54.3(\mathrm{SD}=7.3)$ years and $63.5 \%$ of them were male. Our data showed that patients with macrocytic anemia were older and had higher levels of bilirubin, international normalized ratio (INR) and alkaline phosphatase (ALP) compared to patients with normocytic or microcytic anemia. MELD score was also observed to be higher in the macrocytic group. Oppositely, the total cholesterol and albumin were relatively low. There were no significant differences observed in terms of gender, smoking, drinking, hypertension, systolic blood pressure, diastolic blood pressure, creatinine, eGFR, aspartate aminotransferase (AST) and alanine aminotransferase (ALT). The haemoglobin level and prevalence of diabetes in the microcytic group were slightly different from that in the other two groups, but this difference was negligible.

\section{Assessment of the association between MELD score and possible risk factors}

We next assessed the correlation between the MELD score and possible risk factors using the univariate linear regression analyses (Table 2). Our results revealed a positive association between the MELD score and male, smoking and drinking. In addition, a negative association between the MELD score and the total cholesterol level was observed.

Association between macrocytic anemia and MELD score Patients in the macrocytic group had evidently higher MELD scores than patients in the other two groups (Fig. 2). In univariate regression analysis, we found that there was a significant association between macrocytic anemia and the MELD score (estimated coefficient $[\beta]=$ $2.80,95 \%$ confidence interval $[\mathrm{CI}]: 1.59-4.01, P$ value $[\mathrm{P}]$ $<0.001)$, using the normocytic group as the reference. Furthermore, the association remained robust $(\beta=1.94, \mathrm{CI}$ : $0.81-3.07, P<0.001)$ after adjusting for age, gender, smoking, drinking and total cholesterol in multivariate analysis (Table 2).

\section{Discussion}

In this retrospective study, we demonstrated that macrocytic anemia, defined as anemia in which the RBCs are larger than their normal volume $(100 \mathrm{fL})$, is associated with the severity of liver impairment in patients with HBV-related decompensated cirrhosis. This finding remains substantial even after adjusting for demographics and laboratory parameters, such as age, gender, smoking, drinking and total cholesterol.

An MCV level greater than $100 \mathrm{fL}$, which is also known as macrocytosis, may not always be associated with anemia. Moreover, it presents independently from anemia in most cases [10]. Nevertheless, we chose anemia as one of our inclusion criteria because $84.2 \%$ of the 1445 pre-screened patients have anemia. This result was consistent with the finding of another study, which reported that about $75 \%$ of patients with chronic liver disease have a diverse aetiology of anemia [25]. Furthermore, patients with cirrhosis may have anemia due to a lack of haematopoietic factors, shortened erythrocyte survival, reduced bone marrow function, or gastrointestinal bleeding. All these conditions indicate impaired liver function and a high risk of mortality. Therefore, patients without anemia were excluded from the data analysis to avoid potential bias in our present study.

The importance of macrocytic anemia or macrocytosis seems to be underestimated in the past. Only a few studies focused on its risk of adverse events or death [9-13]. Among these studies, Yoon et al. documented that the elevated MCV level was associated with increased liver cancer mortality in men [13]; this finding was consistent with the result of our study. A small-sample study also found a markedly higher MCV in patients with chronic liver failure than in healthy subjects [26]. These observations, though not directly, provided evidence for our conclusion that patients with HBV-related decompensated cirrhosis 
Table 1 Demographic and biochemical characteristics of the study participants $(N=463)$

\begin{tabular}{|c|c|c|c|c|}
\hline Variable & Macrocytic anemia & Normocytic anemia & Microcytic anemia & $P$ value \\
\hline Number of subjects & 123 & 304 & 36 & \\
\hline Mean corpuscular volume, $\mathrm{fL}$ & $102.7 \pm 2.6$ & $91.2 \pm 5.1^{\dagger}$ & $74.2 \pm 4.6^{\dagger ¥}$ & $<0.001$ \\
\hline Age, years & $56.1 \pm 7.6$ & $53.9 \pm 7.1^{\dagger}$ & $51.8 \pm 6.2^{\dagger}$ & 0.002 \\
\hline Male, n(\%) & $78(63.4)$ & $191(62.8)$ & $25(69.4)$ & 0.738 \\
\hline Drinking, $n(\%)$ & $24(19.5)$ & $74(24.3)$ & 13(36.1) & 0.118 \\
\hline Smoking, n(\%) & 48(39.0) & 107(35.2) & $15(41.7)$ & 0.618 \\
\hline Diabetes, n(\%) & 10(8.1) & $39(12.8)$ & $9(25.0)^{\dagger}$ & 0.026 \\
\hline Hypertension, n(\%) & 14(11.3) & $36(11.8)$ & $4(11.1)$ & 0.985 \\
\hline \multicolumn{5}{|l|}{ Hemoglobin, g/L } \\
\hline$>90$ & $97(78.9)$ & $230(75.7)$ & $10(27.8)^{¥ ¥}$ & $<0.001$ \\
\hline $60-90$ & $21(17.1)$ & $63(20.7)$ & $20(55.6)^{¥ ¥}$ & $<0.001$ \\
\hline$<60$ & $5(4.1)$ & $11(3.6)$ & $6(16.7)^{\dagger ¥}$ & 0.002 \\
\hline Total cholesterol, mmol/L & $2.4 \pm 0.7$ & $2.7 \pm 0.9^{\dagger}$ & $2.7 \pm 0.8$ & 0.012 \\
\hline Systolic blood pressure, $\mathrm{mmHg}$ & $117.9 \pm 17.6$ & $117.8 \pm 15.2$ & $113.8 \pm 13.8$ & 0.350 \\
\hline Diastolic blood pressure, $\mathrm{mmHg}$ & $72.6 \pm 11.7$ & $73.4 \pm 10.0$ & $70.9 \pm 8.6$ & 0.354 \\
\hline Bilirubin, mg/dL & $3.4 \pm 3.4$ & $2.6 \pm 3.2^{\dagger}$ & $1.8 \pm 3.4^{\dagger}$ & 0.011 \\
\hline Creatinine, mg/dL & $0.8 \pm 0.8$ & $0.7 \pm 0.4$ & $0.7 \pm 0.4$ & 0.147 \\
\hline INR & $1.5 \pm 0.3$ & $1.4 \pm 0.4^{\dagger}$ & $1.3 \pm 0.1^{\dagger}$ & 0.006 \\
\hline $\mathrm{eGFR}, \mathrm{mL} / \mathrm{min} / 1.73 \mathrm{~m}^{2}$ & $123.6 \pm 54.5$ & $126.9 \pm 43.4$ & $130.3 \pm 39.1$ & 0.686 \\
\hline Albumin & $27.0 \pm 4.7$ & $29.1 \pm 4.7^{\dagger}$ & $31.7 \pm 4.8^{\dagger ¥}$ & $<0.001$ \\
\hline AST & $78.3 \pm 147.3$ & $84.2 \pm 196.6$ & $41.7 \pm 39.5$ & 0.394 \\
\hline ALT & $45.3 \pm 42.4$ & $59.4 \pm 114.3$ & $29.3 \pm 31.8$ & 0.113 \\
\hline ALP & $122.9 \pm 55.5$ & $106.4 \pm 61.1^{\dagger}$ & $85.2 \pm 32.7^{\dagger}$ & 0.001 \\
\hline MELD score & $10.8 \pm 6.6$ & $8.0 \pm 5.5^{\dagger}$ & $6.3 \pm 5.1^{\dagger}$ & $<0.001$ \\
\hline \multicolumn{5}{|l|}{ Complications, n(\%) } \\
\hline UGB & $6(4.9)$ & $34(11.2)$ & $5(13.9)$ & 0.093 \\
\hline SBP & $36(29.3)$ & $75(24.7)^{\dagger}$ & $3(8.3)^{\dagger}$ & 0.037 \\
\hline $\mathrm{HE}$ & 14(11.4) & $22(7.2)$ & $3(8.3)$ & 0.377 \\
\hline
\end{tabular}

Values are presented as mean \pm standard deviation or numbers (percentage)

INR international normalized ratio, eGFR estimated glomerular filtration rate, $A S T$ aspartate aminotransferase, $A L T$ alanine aminotransferase, $A L P$ alkaline phosphatase, MELD model for end stage liver disease, UGB upper gastrointestinal bleeding, SBP spontaneous bacterial peritonitis, $H E$ hepatic encephalopathy $P$ indicates the difference among the three groups. ${ }^{\dagger}$ Indicates significance $(P<0.05)$ compared to macrocytic anemia; ${ }^{*}$ Indicates significance $(P<0.05)$ compared to normocytic anemia

who have macrocytic anemia were more likely to present worse liver condition.

There are several potential pathological mechanisms that explain why macrocytic anemia is associated with the severity of liver impairment. First, patients with advanced liver damage are more likely to have vitamin $\mathrm{B}_{12}$ or folate deficiencies [27], which directly result in macrocytic anemia. Vitamin $B_{12}$ and folate coenzymes are required for thymidylate and purine synthesis, thus, their deficiencies result in retarded DNA synthesis and eventually will develop into macrocytic anemia [28-30]. Second, macrocytic anemia in liver disease may be due to an increased deposition of cholesterol on the membranes of circulating RBCs [31, 32]. This deposition effectively increases the surface area of the erythrocyte. Third, hemolytic anemias are common in advanced liver failure. In this case, excessive destruction of RBCs and increased reticulocyte count can be observed. The immature erythrocytes are approximately 20\% larger compared to the mature erythrocytes, which result in macrocytic anemia [25]. Moreover, erythrocyte morphology is affected by various factors in liver disease, such as causes, degree of liver damage, and drugs used. Complicated mechanisms, which allow the synchronized performance of their independent or collaborative functions, determine the shape of RBCs. Nevertheless, we firmly believe that there is a positive correlation between macrocytic anemia and the severity of liver impairment in patients with HBV-related decompensated cirrhosis. 
Table 2 Univariate and multivariate linear regression analysis for MELD score

\begin{tabular}{|c|c|c|c|c|}
\hline \multirow[t]{2}{*}{ Variable } & \multicolumn{2}{|l|}{ Univariate } & \multicolumn{2}{|l|}{ Multivariate } \\
\hline & $\beta(\mathrm{Cl} 95 \%)$ & $P$ value & $\beta(\mathrm{Cl} 95 \%)$ & $P$ value \\
\hline Age & $0.05(-0.02,0.13)$ & 0.160 & $0.07(0.01,0.15)$ & 0.028 \\
\hline Male & $2.25(1.15,3.36)$ & $<0.001$ & $1.49(0.29,2.70)$ & 0.015 \\
\hline Smoking & $1.93(0.82,3.03)$ & $<0.001$ & $0.21(-1.03,1.44)$ & 0.742 \\
\hline Drinking & $1.59(0.34,2.85)$ & 0.013 & $0.73(-0.56,2.01)$ & 0.269 \\
\hline Diabetes & $0.53(-1.11,2.16)$ & 0.527 & & \\
\hline Hypertension & $0.15(-1.53,1.84)$ & 0.857 & & \\
\hline \multicolumn{5}{|l|}{ Hemoglobin, g/L } \\
\hline$>90$ & Ref & - & & \\
\hline $60-90$ & $1.09(-0.21,2.39)$ & 0.100 & & \\
\hline$<60$ & $-1.35(-3.90,1.20)$ & 0.298 & & \\
\hline Total cholesterol & $-2.77(-3.37,-2.16)$ & $<0.001$ & $-2.53(-3.14,-1.93)$ & $<0.001$ \\
\hline Systolic blood pressure & $-0.01(-0.04,0.03)$ & 0.863 & & \\
\hline Diastolic blood pressure & $-0.01(-0.06,0.05)$ & 0.900 & & \\
\hline \multicolumn{5}{|l|}{ Anemia classification } \\
\hline Normocytic anemia & Ref & - & Ref & - \\
\hline Macrocytic anemia & $2.80(1.59,4.01)$ & $<0.001$ & $1.94(0.81,3.07)$ & $<0.001$ \\
\hline Microcytic anemia & $-1.73(-3.72,0.27)$ & 0.089 & $-1.77(-3.59,0.05)$ & 0.057 \\
\hline
\end{tabular}

MELD model for end stage liver disease, $\beta$ estimated coefficient, 95\% Cl 95\% confidence interval

In addition, we used the MELD score, which is a formula comprising creatinine, bilirubin, and INR values, to evaluate the severity of liver impairment and risk of death. In our study, patients with macrocytic anemia had higher levels of bilirubin and INR, but no significant difference was observed in creatinine levels and eGFR. Thus, macrocytic anemia might be unrelated to kidney damage in patients with HBV-related decompensated cirrhosis.
There were a few limitations in this study. First, we used the MELD score for evaluating the severity of liver impairment in patients with HBV-related decompensated cirrhosis. Although the MELD score could provide an accurate prediction of short-term mortality of patients with cirrhosis, a follow-up data might be better and more credible. Second, the analysis did not include data on serum vitamin $B_{12}$, folate, reticulocyte count, drugs, and measures of haemolysis, which could

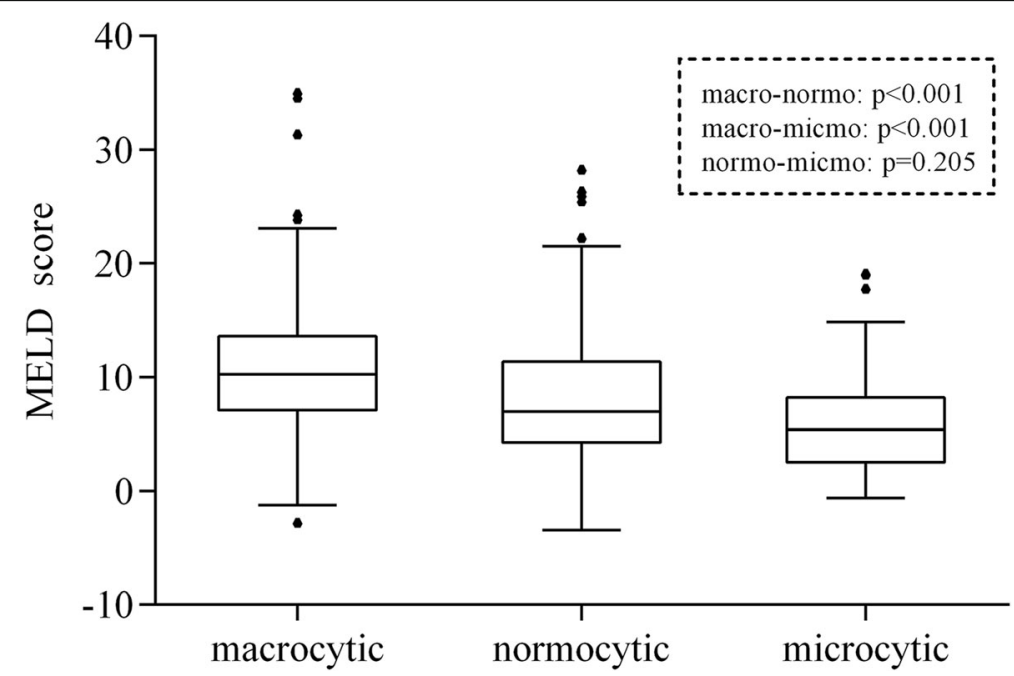

Fig. 2 Anemia types and MELD scores. Patients with macrocytic anemia had evidently higher MELD scores than those with normocytic anemia $(P<0.001)$ or microcytic anemia $(P<0.001)$ 
contribute to better understand the mechanisms of macrocytic anemia in patients with cirrhosis.

\section{Conclusions}

Macrocytic anemia was found to be associated with the severity of liver impairment and might be a predictor for short-term mortality in patients with HBV-related decompensated cirrhosis. However, a large-scale cohort study is recommended to confirm the present results and to elucidate the mechanisms underlying the observed correlations between macrocytic anemia and the severity of liver impairment in patients with HBV-related decompensated cirrhosis.

\section{Abbreviations}

ALP: Alkaline phosphatase; ALT: Alanine aminotransferase; AST: Aspartate aminotransferase; BMI: Body mass index; eGFR: Estimated glomerular filtration rate; HBsAg: Hepatitis B surface antigen; HBV: Hepatitis B virus; HE: Hepatic encephalopathy; INR: International normalised ratio; MCV: Mean corpuscular volume; MDRD: Modification of diet in renal disease; MELD: Model for end stage liver disease; RBCs: Red blood cells; SBP: Spontaneous bacterial peritonitis; UGB: Upper gastrointestinal bleeding

\section{Acknowledgements}

We would like to acknowledge the participants in the study. We appreciated the Department of Epidemiology and Biostatistics, Xi'an Jiaotong University Health Science Center for statistical assistance.

\section{Funding}

There was no funding for this study.

\section{Availability of data and materials}

The datasets used and analysed during the current study will be available from the corresponding author on reasonable request.

\section{Authors' contributions}

$X M, J Y$ and BY designed the study. LY, HL and YF compiled the data and helped with the data interpretation. JY and BY analysed the data and drafted the manuscript. XM, JZ and FZ revised the manuscripts for important intellectual content helped with the data interpretation. All authors reviewed the manuscript.

\section{Ethics approval and consent to participate}

The study was approved by the Ethics Committee of the First Affiliated Hospital, Xi'an Jiaotong University. Since this is a retrospective study, a written consent is waived by the Ethics Committee and is deemed unnecessary.

\section{Consent for publication}

Not applicable

\section{Competing interests}

The authors declare no competing financial interests.

\section{Publisher's Note}

Springer Nature remains neutral with regard to jurisdictional claims in published maps and institutional affiliations.

\section{Author details}

${ }^{1}$ Clinical Research Center, the First Affiliated Hospital, Xi'an Jiaotong University, Xi'an 710061, People's Republic of China. 'Department of Psychiatry, the First Affiliated Hospital, Xi'an Jiaotong University, No.277 Yanta West Road, Yanta District, Xi'an 710061, People's Republic of China. ${ }^{3}$ Center for Translational Medicine, the First Affiliated Hospital, Xi'an Jiaotong University, Xi'an 710061, People's Republic of China.
Received: 21 May 2018 Accepted: 23 October 2018

Published online: 01 November 2018

\section{References}

1. Tsochatzis EA, Bosch J, Burroughs AK. Liver cirrhosis. Lancet. 2014;383(9930): 1749-61.

2. Perz JF, Armstrong GL, Farrington LA, Hutin YJ, Bell BP. The contributions of hepatitis $B$ virus and hepatitis $C$ virus infections to cirrhosis and primary liver cancer worldwide. J Hepatol. 2006:45(4):529-38.

3. Lozano R, Naghavi M, Foreman K, Lim S, Shibuya K, Aboyans V, Abraham J, Adair T, Aggarwal R, Ahn SY, et al. Global and regional mortality from 235 causes of death for 20 age groups in 1990 and 2010: a systematic analysis for the global burden of disease study 2010. Lancet. 2012;380(9859):2095-128.

4. Merican I, Guan R, Amarapuka D, Alexander MJ, Chutaputti A, Chien RN, Hasnian SS, Leung N, Lesmana L, Phiet PH, et al. Chronic hepatitis B virus infection in Asian countries. J Gastroenterol Hepatol. 2000;15(12):1356-61.

5. Srivastava M, Rungta S, Dixit VK, Shukla SK, Singh TB, Jain AK. Predictors of survival in hepatitis B virus related decompensated cirrhosis on tenofovir therapy: an Indian perspective. Antivir Res. 2013;100(2):300-5.

6. Peng $C Y$, Chien RN, Liaw YF. Hepatitis B virus-related decompensated liver cirrhosis: benefits of antiviral therapy. J Hepatol. 2012;57(2):442-50.

7. McMahon BJ. Epidemiology and natural history of hepatitis B. Semin Liver Dis. 2005;25(Suppl 1):3-8.

8. Benoist BD, Mclean E, Egll I, Cogswell M, Benoist BD, Mclean E, Egll I, Cogswell M. Worldwide prevalence of anaemia 1993-2005: WHO global database on anaemia. Geneva, World Health Organization. 2008 2(3):97-100.

9. Ueda T, Kawakami R, Horii M, Sugawara Y, Matsumoto T, Okada S, Nishida T, Soeda T, Okayama S, Somekawa S, et al. High mean corpuscular volume is a new Indicator of prognosis in acute decompensated heart failure. Circ J. 2013;77(11):2766-71.

10. Myojo M, Iwata H, Kohro T, Sato H, Kiyosue A, Ando J, Sawaki D, Takahashi M, Fujita $H$, Hirata $Y$, et al. Prognostic implication of macrocytosis on adverse outcomes after coronary intervention. Atherosclerosis. 2012;221(1): 148-53.

11. Tennankore KK, Soroka SD, West KA, Kiberd BA. Macrocytosis may be associated with mortality in chronic hemodialysis patients: a prospective study. BMC Nephrol. 2011:12:19.

12. Kloth JS, Hamberg P, Mendelaar PA, Dulfer RR, van der Holt B, Eechoute K, Wiemer EA, Kruit WH, Sleijfer S, Mathijssen RH. Macrocytosis as a potential parameter associated with survival after tyrosine kinase inhibitor treatment. Eur J Cancer (Oxford, England : 1990). 2016:56:101-6.

13. Yoon HJ, Kim K, Nam YS, Yun JM, Park M. Mean corpuscular volume levels and all-cause and liver cancer mortality. Clin Chem Lab Med. 2016:54(7): 1247-57.

14. Wiesner R, Edwards E, Freeman R, Harper A, Kim R, Kamath P, Kremers W, Lake J, Howard T, Merion RM, et al. Model for end-stage liver disease (MELD) and allocation of donor livers. Gastroenterology. 2003;124(1):91-6.

15. Bambha K, Kim WR, Kremers WK, Therneau TM, Kamath PS, Wiesner R, Rosen CB, Thostenson J, Benson JT, Dickson ER. Predicting survival among patients listed for liver transplantation: an assessment of serial MELD measurements. Am J Transplant Off J Am Soc Transplant Am Soc Transplant Surg. 2004:4(11):1798-804

16. Kamath PS, Kim WR. Advanced liver disease study G: the model for endstage liver disease (MELD). Hepatology (Baltimore, MD). 2007:45(3):797-805.

17. Murray KF, Carithers RL Jr. AASLD: AASLD practice guidelines: evaluation of the patient for liver transplantation. Hepatology (Baltimore, MD). 2005;41(6): 1407-32.

18. Shim JH, Lee HC, Kim KM, Lim YS, Chung YH, Lee YS, Suh DJ. Efficacy of entecavir in treatment-naive patients with hepatitis B virus-related decompensated cirrhosis. J Hepatol. 2010;52(2):176-82.

19. Jang JW, Choi JY, Kim YS, Woo HY, Choi SK, Lee CH, Kim TY, Sohn JH, Tak $W Y$, Han KH. Long-term effect of antiviral therapy on disease course after decompensation in patients with hepatitis B virus-related cirrhosis. Hepatology (Baltimore, MD). 2015;61(6):1809-20

20. Wang FY, Li B, Li Y, Liu H, Qu WD, Xu HW, Oi JN, Qin CY. Entecavir for patients with hepatitis B decompensated cirrhosis in China: a meta-analysis. Sci Rep. 2016:6:32722

21. Carter BD, Abnet CC, Feskanich D, Freedman ND, Hartge P, Lewis CE, Ockene JK, Prentice RL, Speizer FE, Thun MJ, et al. Smoking and mortality-beyond established causes. N Engl J Med. 2015;372(7):631-40. 
22. Kim HM, Kim BS, Cho YK, Kim Bl, Sohn Cl, Jeon WK, Kim HJ, Park DI, Park JH, Joo KJ, et al. Elevated red cell distribution width is associated with advanced fibrosis in NAFLD. Clin Mol Hepatol. 2013;19(3):258-65.

23. National Kidney Foundation. K/DOQI clinical practice guidelines for chronic kidney disease: evaluation, classification, and stratification. Am J Kidney Dis. 2002;39(2 Suppl 1):S1-266.

24. Ma YC, Zuo L, Chen JH, Luo Q, Yu XQ, Li Y, Xu JS, Huang SM, Wang LN, Huang $W$, et al. Modified glomerular filtration rate estimating equation for Chinese patients with chronic kidney disease. J Am Soc Nephrol. 2006 17(10):2937-44.

25. Gonzalez-Casas R. Spectrum of anemia associated with chronic liver disease World J Gastroenterol. 2009;15(37):4653.

26. Remkova A, Remko M. Homocysteine and endothelial markers are increased in patients with chronic liver diseases. Eur J Intern Med. 2009;20(5):482-6.

27. Rocco A, Compare D, Coccoli P, Esposito C, Di Spirito A, Barbato A, Strazzullo P, Nardone G. Vitamin B12 supplementation improves rates of sustained viral response in patients chronically infected with hepatitis $C$ virus. Gut. 2013;62(5):766-73.

28. Morris MS, Jacques PF, Rosenberg $\mathrm{H}$, Selhub J. Folate and vitamin B-12 status in relation to anemia, macrocytosis, and cognitive impairment in older Americans in the age of folic acid fortification. Am J Clin Nutr. 2007; 85(1):193-200.

29. Green R, Dwyre DM. Evaluation of macrocytic anemias. Semin Hematol. 2015;52(4):279-86.

30. Robinson AR, Mladenovic J. Lack of clinical utility of folate levels in the evaluation of macrocytosis or anemia. Am J Med. 2001;110(2):88-90.

31. Owen JS, Bruckdorfer KR, Day RC, McIntyre N. Decreased erythrocyte membrane fluidity and altered lipid composition in human liver disease. J Lipid Res. 1982;23(1):124-32.

32. Grattagliano I, Calamita G, Cocco T, Wang DQ, Portincasa P. Pathogenic role of oxidative and nitrosative stress in primary biliary cirrhosis. World I Gastroenterol. 2014;20(19):5746-59.

Ready to submit your research? Choose BMC and benefit from:

- fast, convenient online submission

- thorough peer review by experienced researchers in your field

- rapid publication on acceptance

- support for research data, including large and complex data types

- gold Open Access which fosters wider collaboration and increased citations

- maximum visibility for your research: over $100 \mathrm{M}$ website views per year

At $\mathrm{BMC}$, research is always in progress.

Learn more biomedcentral.com/submissions 